\title{
An Analytical Solution for Lateral Buckling Critical Load Calculation of Leaning-Type Arch Bridge
}

\author{
Ai-rong Liu, Yong-hui Huang, Qi-cai Yu, and Rui Rao \\ Guangzhou University-Tamkang University Joint Research Center for Engineering Structure Disaster Prevention and Control, \\ Guangzhou University, Guangzhou 510006, China
}

Correspondence should be addressed to Yong-hui Huang; kunull@foxmail.com

Received 14 March 2014; Revised 1 May 2014; Accepted 1 May 2014; Published 25 May 2014

Academic Editor: Sarp Adali

Copyright (C) 2014 Ai-rong Liu et al. This is an open access article distributed under the Creative Commons Attribution License, which permits unrestricted use, distribution, and reproduction in any medium, provided the original work is properly cited.

An analytical solution for lateral buckling critical load of leaning-type arch bridge was presented in this paper. New tangential and radial buckling models of the transverse brace between the main and stable arch ribs are established. Based on the Ritz method, the analytical solution for lateral buckling critical load of the leaning-type arch bridge with different central angles of main arch ribs and leaning arch ribs under different boundary conditions is derived for the first time. Comparison between the analytical results and the FEM calculated results shows that the analytical solution presented in this paper is sufficiently accurate. The parametric analysis results show that the lateral buckling critical load of the arch bridge with fixed boundary conditions is about 1.14 to 1.16 times as large as that of the arch bridge with hinged boundary condition. The lateral buckling critical load increases by approximately $31.5 \%$ to $41.2 \%$ when stable arch ribs are added, and the critical load increases as the inclined angle of stable arch rib increases. The differences in the center angles of the main arch rib and the stable arch rib have little effect on the lateral buckling critical load.

\section{Introduction}

Leaning-type arch bridge is a relatively new type of spatial tied-arch bridge developed from $\mathrm{x}$-type arch bridge. It is composed of two load-bearing ribs (called main arch ribs) which are perpendicular to the bridge deck and two leaning arch ribs (called stable arch ribs) on the sides of the main arch ribs. These two types of arch ribs constitute a space stable system when connected by transverse braces between them. This type of bridge is one of the most competitive urban bridges because it is stylish and unique, gives an open and clear view for drivers, and is economically efficient. As the vertical stiffness of the main arch rib is much higher than that of the stable arch rib, the major portion of the dead and live loads is supported by the main arch ribs. Stable arch rib supports only a small portion of the live load, and its main function is to assure the lateral stability of the main arch rib. Because there are no transverse braces placed between the main arch ribs, and the stable arch rib's contribution to the improvement of the lateral stability of bridge is very limited, the lateral stability often becomes a key factor deciding the bridge's safety [1]. The world's first leaning-type arch bridge named
Bacde Road Bridge was built in 1992 in Barcelona. It was designed by the Spanish architect, Santiago Calatrava. This bridge is $52 \mathrm{~m}$ long, $25.8 \mathrm{~m}$ wide, and the inclined angle of stable arch rib is $30^{\circ}$. The vertical main arch ribs are hinged and the inclined stable arch ribs are fixed at both ends [2]. Over the past decades, leaning-type arch bridges have developed rapidly. At present, more than 20 leaning-type arch bridges have been built around the world, most of them in China. Usually, fixed boundary conditions are adopted for both the main and stable arch ribs, such as the Kangfu Bridge in Yiyang city, China, Hanjiang North Bridge in Chaozhou city, China, and Shengli Bridge in Jiangmen city, China (Figure 1). However, under special circumstances, in order to reduce main arch rib's internal force and horizontal thrust or adapt to the local environmental conditions [3], hinged boundary condition is applied at the arch ends of the main arch, such as Yufeng Bridge in Kunshan city, China, and Danxi Bridge in Yiwu city, China.

At present, the derivation of the analytical solution of the arch structure's buckling problem is mainly focused on the individual arch rib or conventional arch bridges with symmetrical arch ribs. Closed-form solutions for out-of-plane 


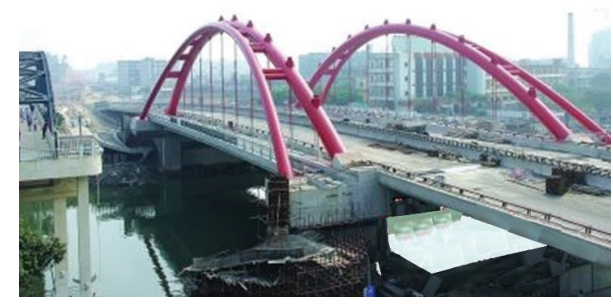

(a)

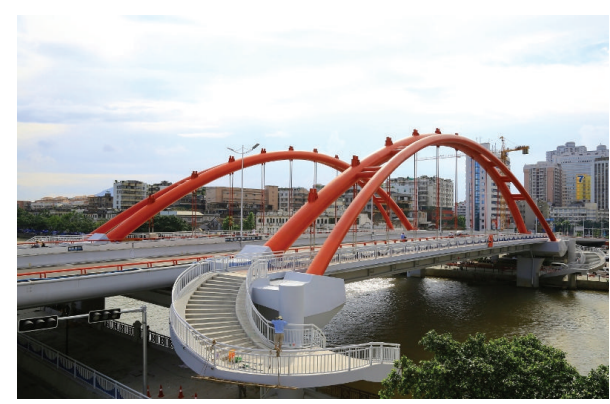

(b)

Figure 1: Shenli Bridge in Jiangmen City of China.

buckling of arches, subjected to uniform bending or uniform compression, were obtained by Lim and Kang [4]. Pi et al. $[5,6]$ investigated the flexural torsional buckling of shallow arches with an open thin-walled section, subjected to a radial load uniformly distributed around the arch axis. In-plane static and dynamic buckling of shallow pin-ended parabolic arches with a horizontal cable was investigated by Chen and Feng [7]. La et al. [8] presented an experimental investigation of the elastic-plastic out-of-plane buckling response of roller bent circular steel arches subjected to a single force applied to the crown. Bradford and Pi [9] derived a new unified analytical solution for the lateral-torsional buckling load of pin-ended arches by accounting for the combined bending and axial compressive action. Dou et al. [10] investigated the sectional rigidities of trusses and the out-ofplane buckling loads of pin-ended circular steel tubular truss arches in uniform axial compression and in uniform bending. In addition, Jin and Zhao [11] derived the lateral buckling critical load for X-type twin ribbed arch braced with transverse beams. Moreover, Liu and Lu [12] derived the analytical solution of the lateral buckling critical load for the conventional tied-arch bridge with transverse braces and discussed the effect of structural parameters on lateral stability. Additionally, Xiang [13] presented a formula of the lateral buckling critical load for a half-through bridge at service stage and the effect of beam location for vehicle lane on the stability of this type of bridge was further studied.

Compared with individual arch rib or conventional arch bridges with symmetrical arch ribs, the leaning-type arch rib system is different in several aspects including an inclined angle between the main and stable arch ribs, different stiffness of main and stable arch ribs, more significant spatial effect, and more complicated loading conditions. These factors result in difficulties in deriving the analytical solution of the lateral buckling critical load. Especially that the mechanical model of transverse brace is very different from those of the conventional arch bridge when a lateral buckling occurs. Presently, researchers have conducted preliminary studies on the lateral stability of leaning-type arch bridge based on finite element method (FEM) [14]. The derivation of the analytical solution formula of the lateral buckling critical load of leaning-type arch ribs system has been preliminarily studied by Liu et al. [15]. However, in their studies the influence of the bridge deck system and hanger tensions on leaning-type arch bridge was not taken into consideration. The central angles of the main and stable arch ribs were assumed to be the same in their studies, but in fact they are different in some conditions. And in their studies the inclined angles of stable arch ribs should be less than 15 degrees, while the inclined angles larger than 15 degrees; the precision of the solution is bad. Compared with the FEM calculation results, the relationship among different design parameters of the bridge can be clearly revealed by the analytical solution and the optimization of structure design is made easier; the complicated process of constructing the FE model can also be simplified.

In order to consider the influence of the components of leaning-type arch bridge comprehensively, the global transverse brace deformation parameter $\beta$ is considered and the central angles of the main arch ribs and stable arch ribs are assumed different, and the tangential and radial mechanical models of the transverse brace between the main and stable arch ribs are established, then the analytical solution of the lateral buckling critical load for leaning-type arch rib system is derived in this paper. Compared with the analytical solution derived by Liu et al. [15], the one derived in this paper has a wider scope of applications. The deformation energy of the main arch rib, stable arch rib, and transverse braces between them are constructed; and the potential energy caused by the hangers tensions are also established for both the main arch rib and stable arch rib under fixed and hinged boundary conditions. And the total potential energy of the bridge in a buckling process is obtained thereafter. Based on the stationary energy principle, the analytical solution for the lateral buckling critical load of leaning-type arch bridge is obtained. In the end, parametric analysis is carried out in order to investigate how changes in certain design parameters would affect the critical load of the leaning-type arch bridges, which could lead to an optimum design of this type of bridge structures.

\section{Lateral Buckling Critical Load under the Fixed Boundary Condition of Main Arch Rib}

2.1. Calculation Model of Leaning-Type Arch Bridge. The following assumptions are made in the derivation process: 


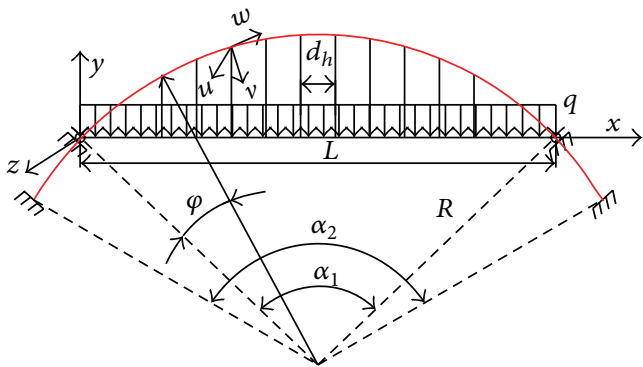

(a) Elevation view

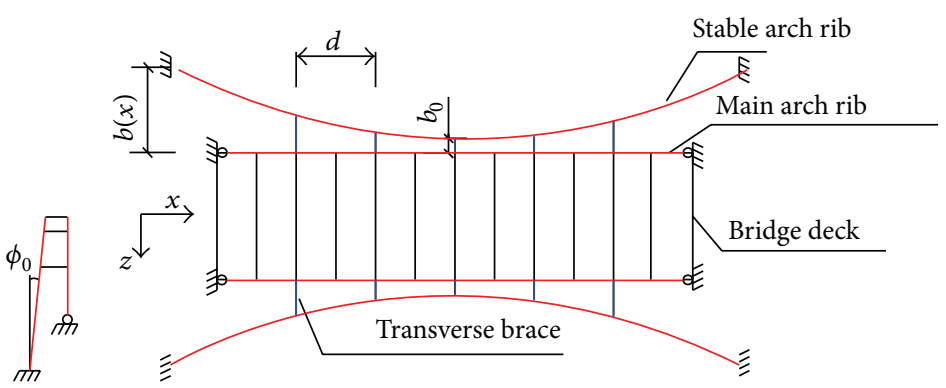

(c) Plan view (b)

Side
view (c) Plan view

FIGURE 2: Calculation sketch of leaning-type arch bridge.

(1) the main arch ribs and the stable arch ribs are fixed in their ends; (2) the axis of main and stable arch ribs are arcshaped curves; (3) the stiffness of arch ribs and transverse braces are constants; (4) the axial deformation of arch rib in the buckling process is neglected; (5) the external load is evenly and vertically distributed along the bridge deck and is transmitted to the arch rib via the hangers; and (6) the force acting on arch ribs satisfies the film tension assumption.

The simplified calculation model of a leaning-type arch bridge is shown in Figure 2. In the figure, $x-y-z$ is the global coordinate system and $u-v-w$ is the local coordinate system. $u, v$, and $w$ represent the lateral, radial, and tangential displacement of arch ribs, respectively, $\phi_{0}$ represents the angle between the main arch rib and the stable $\operatorname{arch} \operatorname{rib}, \varphi$ is the angle of a position in the arch ribs, $\alpha_{1}$ is the central angle of the main arch ribs, $\alpha_{2}$ is the central angle of the stable arch rib, and $R$ is the radius of the main and stable arch ribs. $b(x)$ is the distance between the main arch rib and the stable arch rib. In the arch crown position the distance is $b_{0}$ and $b(x)=b_{0}+2 R \sin \phi_{0}(1-\cos \varphi)$. The transverse braces between the main and stable arch ribs are equidistant with a distance of $d$; the hangers are also arranged equidistantly with a distance of $d_{h}$.

According to the basic assumption and calculation scheme, the relationship between the lateral displacement $u_{1}^{I}$, $u_{2}^{I I}$ and the radial displacement $v_{1}^{I}, v_{2}^{I I}$ of the main arch ribs and the stable arch ribs under the local coordinate is given, respectively, as

$$
\begin{aligned}
& u_{1}^{I}=u_{1}, \quad u_{2}^{I I}=\frac{y_{02}^{\prime}}{y_{01}^{\prime}+y_{02}^{\prime}} b(x) \beta \sin \varphi_{0}+u_{1} \cos \varphi_{0} \\
& v_{1}^{I}=\frac{y_{01}^{\prime}}{y_{01}^{\prime}+y_{02}^{\prime}} b(x) \beta, \\
& v_{2}^{I I}=-\frac{y_{02}^{\prime}}{y_{01}^{\prime}+y_{02}^{\prime}} b(x) \beta \cos \varphi_{0}+u_{1} \sin \varphi_{0},
\end{aligned}
$$

where $u_{1}$ represents the lateral displacement of the arch axis of the main arch, $\beta$ represents the global torsional angle of the transverse brace caused by deformation of arch rib in radial plane, $b(x)$ is the distance between the main arch rib, and $y_{01}^{\prime}$ and $y_{02}^{\prime}$ represent the distance from the contraflexure point of

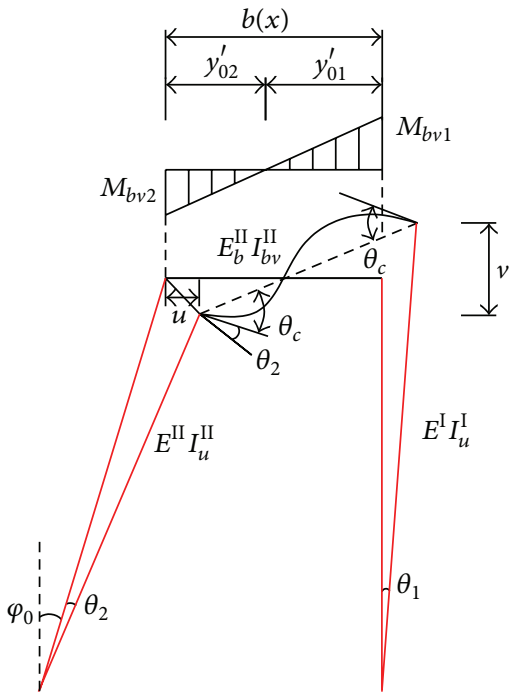

FIGURE 3: Radial bending deformation of transverse brace.

transverse brace's radial deformation to the main and stable arch ribs, respectively (shown in Figure 3 ).

When there is a lateral deformation in the arch rib system, axial strain of the main arch is given as

$$
\varepsilon=-\frac{v_{1}^{I}}{R}+\frac{d w_{1}^{I}}{d s}+\frac{1}{2}\left[\left(\frac{d u_{1}^{I}}{d s}\right)^{2}+\left(\frac{d v_{1}^{I}}{d s}\right)^{2}\right],
$$

where $w_{1}^{I}$ represents the tangential displacement of the main arch ribs under the local coordinate.

According to the basic assumption $\varepsilon=0$,

$$
\frac{d w_{1}^{I}}{d s}=\frac{v_{1}^{I}}{R}-\frac{1}{2}\left[\left(\frac{d u_{1}^{I}}{d s}\right)^{2}+\left(\frac{d v_{1}^{I}}{d s}\right)^{2}\right] .
$$

Because the arches are fixed at both ends, $\int_{s} d w_{1}^{I}=0$, so

$$
\int_{s}\left(\frac{v_{1}^{I}}{R}\right) d s=\frac{1}{2} \int_{s}\left(\frac{d u_{1}^{I}}{d s}\right)^{2} d s+\frac{1}{2} \int_{s}\left(\frac{d v_{1}^{I}}{d s}\right)^{2} d s .
$$


Assuming the ends of the main arch rib and the stable arch rib are perfectly fixed, the torsional angle and the lateral displacements of arch axis of the main and stable arch ribs are given, respectively, as

$$
\begin{aligned}
& \theta_{1}=C_{1}\left(1-\cos \frac{2 \pi \varphi}{\alpha_{1}}\right) \\
& \theta_{2}=C_{3}\left(1-\cos \frac{2 \pi \varphi}{\alpha_{2}}\right), \\
& u_{1}=C_{2}\left(1-\cos \frac{2 \pi \varphi}{\alpha_{1}}\right) \\
& u_{2}=C_{2}\left(1-\cos \frac{2 \pi \varphi}{\alpha_{2}}\right) .
\end{aligned}
$$

The lateral displacement of bridge deck system is given as

$$
u_{d}=C_{4}\left(1-\cos \frac{2 \pi \varphi}{\alpha_{1}}\right) .
$$

The global torsional angle of the transverse brace caused by deformation of arch rib in radial plane is given as

$$
\beta=C_{5}\left(1-\cos \frac{2 \pi \varphi}{\alpha_{1}}\right) .
$$

The above equations satisfy the following displacement boundary conditions.

(1) When $\varphi=0$ and $\varphi=\alpha_{1}, \theta_{1}=0, \theta_{1}^{\prime}=0, u_{1}=u_{d}=$ $\beta=0$, and $u_{1}^{\prime}=u_{d}^{\prime}=\beta^{\prime}=0$.

(2) When $\varphi=0$ and $\varphi=\alpha_{2}, \theta_{2}=0, \theta_{2}^{\prime}=0, u_{2}=0$, and $u_{2}^{\prime}=0$.

The lateral deflection curvatures along the $v$ axis of the main and stable arch ribs are given as [16]

$$
\begin{aligned}
K_{u}^{I} & =\frac{\theta_{1}}{R}-\frac{d^{2} u_{1}^{I}}{d s^{2}}, \\
K_{u}^{I I} & =\frac{\theta_{2}}{R}-\frac{d^{2} u_{2}^{I I}}{d s^{2}},
\end{aligned}
$$

where $K_{v}^{I}$ and $K_{v}^{I I}$ represent the lateral deflection curvature along $v$ axis of the main and stable arch ribs respectively.

The torsional deflection curvatures along $w$ axes are also given as [16]

$$
\begin{aligned}
& K_{w}^{I}=\frac{d \theta_{1}}{d s}+\frac{1}{R} \frac{d^{2} u_{1}^{I}}{d s}, \\
& K_{w}^{I I}=\frac{d \theta_{2}}{d s}+\frac{1}{R} \frac{d u_{2}^{I I}}{d s},
\end{aligned}
$$

where $K_{w}^{I}$ and $K_{w}^{I I}$ represent the torsional deflection curvatures along $w$ axes of the main and stable arch ribs, respectively.
2.2. Energy Equations. The lateral deformation energy of a leaning-type arch bridge can be written as

$$
\begin{aligned}
W= & U_{u}^{I}+U_{u}^{I I}+U_{w}^{I}+U_{w}^{I I}+U_{c u}^{I}+U_{c u}^{I I}+U_{b H} \\
& +U_{b v}+V_{H}+U_{d}+V
\end{aligned}
$$

where $U_{u}^{I}, U_{u}^{I I}, U_{w}^{I}, U_{w}^{I I}, U_{c u}^{I}$, and $U_{c u}^{I I}$ represent the total lateral bending deformation energy, torsional deformation energy, and local bending deformation energy of the main and stable arch ribs, respectively; $U_{b v}$ and $U_{b H}$ are the bending deformation energy of the transverse braces in radial and tangential directions along the main arch rib's axis; $V_{H}$ is the elastic potential energy caused by the horizontal part of the tension of the hangers; $U_{d}$ represents the elastic potential energy of bridge deck system; and $V$ represents the potential energy of external loading applied to the arch bridge.

The total lateral bending deformation energy of the main and stable arch ribs are given in

$$
\begin{aligned}
U_{u}^{I}+U_{u}^{I I}= & \frac{1}{2} E^{I} I_{u}^{I} \int_{s_{1}}\left(K_{u}^{I}\right)^{2} d s+\frac{1}{2} E^{I I} I_{u}^{I I} \int_{s_{2}}\left(K_{u}^{I I}\right)^{2} d s \\
= & \frac{1}{2} E^{I} I_{u}^{I}\left[C_{1}^{2} A_{11}+\frac{C_{2}^{2}}{R^{3}} A_{12}+\frac{C_{1} C_{2}}{R^{2}} A_{13}\right] \\
& +\frac{1}{2} E^{I I} I_{u}^{I I}\left[\frac{C_{2}^{2}}{R^{3}} A_{21}+\frac{C_{3}^{2}}{R} A_{22}+\frac{C_{5}^{2}}{R} A_{23}\right. \\
& \left.+\frac{C_{2} C_{3}}{R^{2}} A_{24}+\frac{C_{2} C_{5}}{R^{2}} A_{25}+\frac{C_{3} C_{5}}{R} A_{26}\right],
\end{aligned}
$$

where $E^{I} I_{u}^{I}$ and $E^{I I} I_{u}^{I I}$ are the lateral bending stiffness of the main and stable arch ribs. Consider the following:

$$
\begin{aligned}
& A_{11}=\int_{0}^{\alpha_{1}}\left(1-\cos \frac{2 \pi \varphi}{\alpha_{1}}\right)^{2} d \varphi \\
& A_{12}=\int_{0}^{\alpha_{1}}\left(\frac{2 \pi}{\alpha_{1}}\right)^{4} \cos ^{2} \frac{2 \pi \varphi}{\alpha_{1}} d \varphi \\
& A_{13}=\int_{0}^{\alpha_{1}}-2\left(\frac{2 \pi}{\alpha_{1}}\right)^{2}\left(1-\cos \frac{2 \pi \varphi}{\alpha_{1}}\right) \cos \frac{2 \pi \varphi}{\alpha_{1}} d \varphi \\
& A_{21}=\int_{0}^{\alpha_{2}} \cos \phi_{0}\left(\frac{2 \pi}{\alpha_{2}}\right)^{4} \cos ^{2} \frac{2 \pi \varphi}{\alpha_{1}} d \varphi \\
& A_{22}=\int_{0}^{\alpha_{2}}\left(1-\cos \frac{2 \pi \varphi}{\alpha_{2}}\right)^{2} d \varphi
\end{aligned}
$$




$$
\begin{aligned}
A_{23}= & \int_{0}^{\alpha_{2}} \frac{1}{R^{2}}\left(\frac{2 \pi}{\alpha_{1}}\right)^{4} \frac{b(x)^{2} \sin ^{2} \phi_{0}}{\left(1+e_{2}\right)^{2}} \cos ^{2} \frac{2 \pi \varphi}{\alpha_{1}} d \varphi \\
A_{24}= & \int_{0}^{\alpha_{2}}-2 \cos \phi_{0}\left(\frac{2 \pi}{\alpha_{2}}\right)^{2} \cos \frac{2 \pi \varphi}{\alpha_{2}}\left(1-\cos \frac{2 \pi \varphi}{\alpha_{2}}\right) d \varphi \\
A_{25}= & \int_{0}^{\alpha_{2}} \frac{2 b(x) \sin \phi_{0} \cos \phi_{0}}{R\left(1+e_{2}\right)} \\
& \times\left(\frac{2 \pi}{\alpha_{1}}\right)^{2}\left(\frac{2 \pi}{\alpha_{2}}\right)^{2} \cos \frac{2 \pi \varphi}{\alpha_{1}} \cos \frac{2 \pi \varphi}{\alpha_{2}} d \varphi \\
A_{26}= & \int_{0}^{\alpha_{2}}-\frac{2 b(x) \sin \phi_{0}}{R\left(1+e_{2}\right)}\left(\frac{2 \pi}{\alpha_{1}}\right)^{2} \cos \frac{2 \pi \varphi}{\alpha_{1}}\left(1-\cos \frac{2 \pi \varphi}{\alpha_{2}}\right) d \varphi .
\end{aligned}
$$

The torsional deformation energy of the main and stable arch ribs is given in

$$
\begin{aligned}
U_{w}^{I}+U_{w}^{I I}= & \frac{1}{2} G^{I} T^{I} \int_{s_{1}}\left(K_{w}^{I}\right)^{2} d s+\frac{1}{2} G^{I I} T^{I I} \int_{s_{2}}\left(K_{w}^{I I}\right)^{2} d s \\
= & \frac{1}{2} G^{I} T^{I}\left[\frac{C_{1}^{2}}{R} B_{11}+\frac{C_{2}^{2}}{R^{3}} B_{12}+\frac{C_{1} C_{2}}{R^{2}} B_{13}\right] \\
& +\frac{1}{2} G^{I I} T^{I I}\left[\frac{C_{2}^{2}}{R^{3}} B_{21}+\frac{C_{3}^{2}}{R} B_{22}+\frac{C_{5}^{2}}{R} B_{23}\right. \\
& \left.+\frac{C_{2} C_{3}}{R^{2}} B_{24}+\frac{C_{2} C_{5}}{R^{2}} B_{25}+\frac{C_{3} C_{5}}{R} B_{26}\right],
\end{aligned}
$$

where $G^{I} T^{I}$ and $G^{I I} T^{I I}$ are the torsional stiffness of the main and stable arch ribs. Consider the following:

$$
\begin{aligned}
& B_{11}=\int_{0}^{\alpha_{1}}\left(\frac{2 \pi \varphi}{\alpha_{1}}\right)^{2} \sin ^{2} \frac{2 \pi \varphi}{\alpha_{1}} d \varphi \\
& B_{12}=\int_{0}^{\alpha_{1}}\left(\frac{2 \pi}{\alpha_{1}}\right)^{2} \sin ^{2} \frac{2 \pi \varphi}{\alpha_{1}} d \varphi \\
& B_{13}=\int_{0}^{\alpha_{1}} 2\left(\frac{2 \pi}{\alpha_{1}}\right)^{2} \sin ^{2} \frac{2 \pi \varphi}{\alpha_{1}} d \varphi \\
& B_{21}=\int_{0}^{\alpha_{2}} \cos ^{2} \phi_{0}\left(\frac{2 \pi}{\alpha_{2}}\right)^{4} \sin ^{2} \frac{2 \pi \varphi}{\alpha_{1}} d \varphi \\
& B_{22}=\int_{0}^{\alpha_{2}}\left(\frac{2 \pi}{\alpha_{2}}\right)^{2} \sin ^{2} \frac{2 \pi \varphi}{\alpha_{2}} d \varphi \\
& B_{23}=\int_{0}^{\alpha_{2}} \frac{1}{R^{2}}\left(\frac{2 \pi}{\alpha_{1}}\right)^{2} \frac{b(x)^{2} \sin ^{2} \phi_{0}}{\left(1+e_{2}\right)^{2}} \sin ^{2} \frac{2 \pi \varphi}{\alpha_{1}} d \varphi \\
& B_{24}=\int_{0}^{\alpha_{2}} 2 \cos \phi_{0}\left(\frac{2 \pi}{\alpha_{2}}\right)^{2} \sin ^{2} \frac{2 \pi \varphi}{\alpha_{2}} d \varphi
\end{aligned}
$$

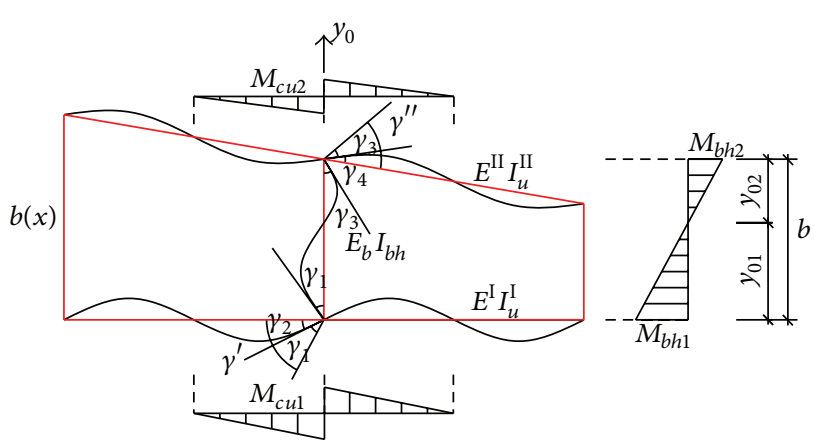

FIGURE 4: Bending deformation of arch ribs and transverse braces.

$$
\begin{aligned}
& B_{25}=\int_{0}^{\alpha_{2}} \frac{2 b(x) \sin \phi_{0} \cos \phi_{0}}{R\left(1+e_{2}\right)} \frac{2 \pi}{\alpha_{1}} \frac{2 \pi}{\alpha_{2}} \sin \frac{2 \pi \varphi}{\alpha_{1}} \sin \frac{2 \pi \varphi}{\alpha_{2}} d \varphi \\
& B_{26}=\int_{0}^{\alpha_{2}} \frac{2 b(x) \sin \phi_{0}}{R\left(1+e_{2}\right)} \frac{2 \pi}{\alpha_{1}} \frac{2 \pi}{\alpha_{2}} \sin \frac{2 \pi \varphi}{\alpha_{1}} \sin \frac{2 \pi \varphi}{\alpha_{2}} d \varphi .
\end{aligned}
$$

Transverse brace bending deformation occurs in the tangential direction along arch axis when there is a lateral buckling in the arch rib system as shown in Figure 4. In this case, the tangential bending deformation energy of the single transverse brace is given as

$$
\bar{U}_{b H}=\frac{1}{2 E_{b} I_{b h}} \int_{0}^{y_{01}} M_{b h 1}^{2} d y_{0}+\frac{1}{2 E_{b} I_{b h}} \int_{0}^{y_{02}} M_{b h 2}^{2} d y_{0},
$$

where $E_{b} I_{b h}$ is transverse brace's bending stiffness along tangential direction of arch rib and $y_{01}$ and $y_{02}$ represent the distances from the contraflexure point of transverse brace tangential deformation to the main and stable arch ribs, respectively. Therefore, the length of transverse brace is $b(x)=y_{01}+y_{02}$.

From Figure 4, the tangential bending moment of transverse brace near the main and stable arch ribs is given by the superposition principle.

$$
\begin{aligned}
& M_{b h 1}=\frac{4 E_{b} I_{b h}}{b} \gamma_{1}+\frac{2 E_{b} I_{b h}}{b} \gamma_{3}, \\
& M_{b h 2}=\frac{2 E_{b} I_{b h}}{b} \gamma_{1}+\frac{4 E_{b} I_{b h}}{b} \gamma_{3},
\end{aligned}
$$

where $\gamma_{1}$ represents the tangential angular rotation of the transverse brace at the intersection points between the main arch rib and the transverse brace and $\gamma_{3}$ represents the tangential angular rotation of the transverse brace at the intersection points between the stable arch rib and the transverse brace.

It can be further derived as

$$
\begin{aligned}
& y_{01}=\frac{2 \gamma_{1}+\gamma_{3}}{3\left(\gamma_{1}+\gamma_{3}\right)} b(x), \\
& y_{02}=\frac{\gamma_{1}+2 \gamma_{3}}{3\left(\gamma_{1}+\gamma_{3}\right)} b(x),
\end{aligned}
$$


$b(x)$ can be replaced by a constant $h$, which is the distance between the main and stable arch ribs at quarter span for calculation simplification. Although the length of transverse brace $b(x)$ is not a constant, the length of the transverse brace $h$ at quarter span is very close to the average length of the transverse braces of the entire bridge. Such simplification can make the derivation process become simple.

The values of $y_{01}$ and $y_{02}$ are closely related to the bending stiffness of arch ribs, panel length, bending stiffness, and length of transverse braces. Due to the inclined angle and the different stiffness of leaning-type arch bridge's main and stable arch ribs, the tangential and radial deformation of the transverse brace between the main and stable arch ribs differ from that of the conventional arch bridges. It is not a simple "S" shape. For leaning-type arch bridges, bending stiffness of the main arch rib is larger than that of the stable arch rib, so $y_{01}>y_{02}$, as shown in Figure 4 , as an exceptional case, for conventional arch bridges, $y_{01}=y_{02}$. In order to obtain the relationship between $y_{01}, y_{02}$, a tangential mechanical model of transverse brace along the arch axis is established when a lateral buckling occurs, as shown in Figure 5(a); its corresponding bending moment is shown in Figure 5(b), from which (19) can be given as

$$
\frac{M_{b h 1}}{M_{b h 2}}=\frac{E^{I} E_{b} I_{u}^{I} I_{b h} d+6 E^{I} E^{I I} I_{u}^{I} I_{u}^{I I} b(x) \cos \phi_{0}}{6 E^{I} E^{I I} I_{u}^{I} I_{u}^{I I} b(x) \cos \phi_{0}+E^{I I} E_{b} I_{u}^{I I} I_{b h} d \cos \phi_{0}}=e_{1},
$$

where $e_{1}$ is a constant.

From (17) and (19), it can be obtained that

$$
\frac{M_{b h 1}}{M_{b h 2}}=\frac{2 \gamma_{1}+\gamma_{3}}{\gamma_{1}+2 \gamma_{3}}=e_{1} .
$$

Assuming $\gamma_{3}=a_{1} \gamma_{1}$, then

$$
a_{1}=\frac{\gamma_{3}}{\gamma_{1}}=\frac{2-e_{1}}{2 e_{1}-1}
$$

thus, from (18) and (21), the relationship of $y_{01}$ and $y_{02}$ can be obtained as

$$
y_{01}=\frac{2+a_{1}}{1+2 a_{1}} y_{02}
$$

Substituting (17) and (18) into (16), the equation of tangential bending energy of the transverse braces in the full arch rib range is given as

$$
\begin{aligned}
U_{b H}=\int_{s} \frac{\bar{U}_{b H}}{d} d s & \frac{2 E_{b} I_{b h}}{9 d h}\left[\int_{s_{1}} \frac{2 \gamma_{1}+\gamma_{3}}{\gamma_{1}+\gamma_{3}}\left(4 \gamma_{1}^{2}+4 \gamma_{1} \gamma_{3}+\gamma_{3}^{2}\right) d s\right. \\
& \left.+\int_{s_{2}} \frac{\gamma_{1}+2 \gamma_{3}}{\gamma_{1}+\gamma_{3}}\left(\gamma_{1}^{2}+4 \gamma_{1} \gamma_{3}+4 \gamma_{3}^{2}\right) d s\right] .
\end{aligned}
$$

When the tangential local deformation occurs in the main and stable arch ribs, assuming the bending moments of the main and stable arch ribs along the radial direction are $M_{c u 1}$ and $M_{c u 2}$, respectively, the single-panel section arch rib's local bending energy of the main and stable arch ribs can be expressed as

$$
\begin{aligned}
\bar{U}_{c u}^{I}+\bar{U}_{c u}^{I I} & =\frac{1}{2 E^{I} I_{u}^{I}} \int_{d} M_{c u 1}^{2} d x_{0}+\frac{1}{2 E^{I I} I_{u}^{I I}} \int_{d} M_{c u 2}^{2} d x_{0} \\
& =\frac{6 E^{I} I_{u}^{I}}{d} \gamma_{2}^{2}+\frac{6 E^{I I} I_{u}^{I I}}{d} \gamma_{4}^{2} .
\end{aligned}
$$

If the local bending energy of each single-panel section arch rib is the same, the full-arch-rib local bending deformation energy can be written as

$$
\begin{aligned}
U_{c u}^{I}+U_{c u}^{I I} & =\int_{s} \frac{\bar{U}_{c u}^{I}}{d} d s+\int_{s} \frac{\bar{U}_{c u}^{I I}}{d} d s \\
& =\int_{s} \frac{3 E_{b} I_{b h}}{d h} \gamma_{1} \gamma_{2} d s+\int_{s} \frac{3 E_{b} I_{b h}}{d h} \gamma_{3} \gamma_{4} d s .
\end{aligned}
$$

It could be obtained from Figure 4 that

$$
2 M_{c u 1}=M_{b h 1}, \quad 2 M_{c u 2}=M_{b h 2} .
$$

Therefore, from (23), (25), and (26), the local bending energy of arch rib and the tangential bending energy of transverse brace are obtained as

$$
\begin{aligned}
U_{b H}+U_{c u}^{I}+U_{c u}^{I I}= & \frac{3 E_{b} I_{b h}}{d h} \int_{s_{1}}\left(N_{1} \eta_{1}+\eta_{2}\right) \eta_{1} \gamma^{\prime 2} d s \\
& +\frac{3 E_{b} I_{b h}}{d h} \int_{s_{2}}\left(N_{2} \eta_{3}+\eta_{4}\right) \eta_{3} \gamma^{\prime \prime 2} d s \\
= & E_{b} I_{b h} \frac{C_{2}^{2}}{R^{3}} D_{1}+E_{b} I_{b h} \frac{C_{2}^{2}}{R^{3}} D_{2},
\end{aligned}
$$

where

$$
\begin{aligned}
D_{1} & =\frac{3 n}{b s}\left(N_{1} \eta_{1}+\eta_{2}\right) \eta_{1} \int_{0}^{\alpha_{1}} R^{2}\left(\frac{2 \pi}{\alpha_{2}}\right)^{2} \sin ^{2} \frac{2 \pi \varphi}{\alpha_{1}} d \varphi, \\
D_{2} & =\frac{3 n}{b s}\left(N_{2} \eta_{3}+\eta_{4}\right) \eta_{3} \int_{0}^{\alpha_{2}} R^{2}\left(\frac{2 \pi}{\alpha_{2}}\right)^{2} \sin ^{2} \frac{2 \pi \varphi}{\alpha_{2}} d \varphi, \\
\gamma^{\prime} & =\gamma_{1}+\gamma_{2}, \\
\gamma^{\prime \prime} & =\gamma_{3}+\gamma_{4}, \\
\eta_{1} & =\frac{\gamma_{1}}{\gamma^{\prime}}=\frac{1}{1+\left(d E_{b} I_{b h}\right) /\left(2 h E^{I} I_{u}^{I}\right)},
\end{aligned}
$$




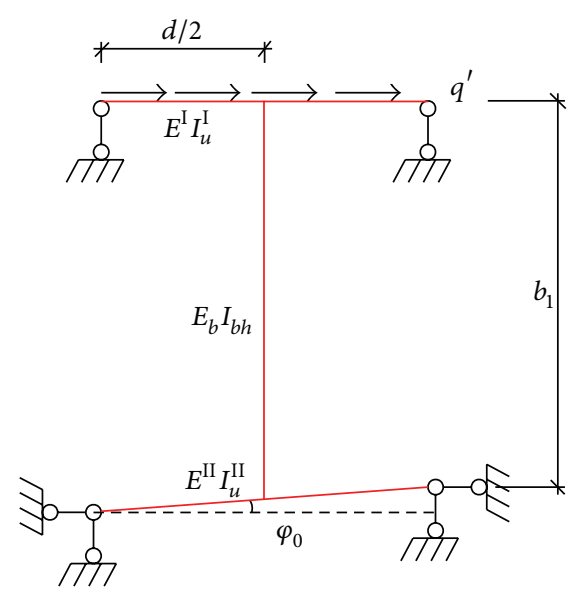

(a) Mechanical model

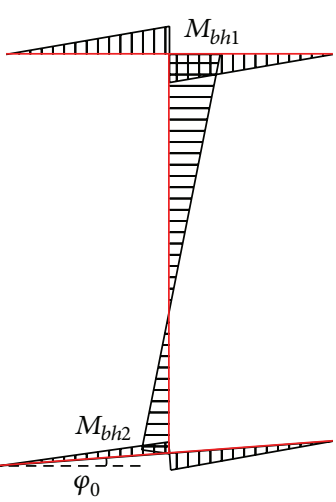

(b) Bending moment diagram

FIGURE 5: Mechanical model and bending moment diagram in tangential direction.

$$
\begin{aligned}
& \eta_{2}=\frac{\gamma_{2}}{\gamma^{\prime}}=\frac{1}{1+\left(2 h E^{I} I_{u}^{I}\right) /\left(d E_{b} I_{b h}\right)}, \\
& \eta_{3}=\frac{\gamma_{3}}{\gamma^{\prime \prime}}=\frac{1}{1+\left(d E_{b} I_{b h}\right) /\left(2 h E^{I I} I_{u}^{I I}\right)}, \\
& \eta_{4}=\frac{\gamma_{4}}{\gamma^{\prime \prime}}=\frac{1}{1+\left(2 h E^{I I} I_{u}^{I I}\right) /\left(d E_{b} I_{b h}\right)}, \\
& N_{1}=\frac{2}{27} \cdot \frac{\left(a_{1}+2\right)}{\left(a_{1}+1\right)}\left(4+4 a_{1}+a_{1}^{2}\right), \\
& N_{2}=\frac{2}{27} \cdot \frac{\left(1 / a_{1}+2\right)}{\left(1 / a_{1}+1\right)}\left(\frac{1}{a_{1}^{2}}+\frac{4}{a_{1}}+4\right) .
\end{aligned}
$$

The mechanical model and moment diagram of arch ribs and transverse brace in radial direction are shown in Figure 3. And the radial deformation energy of a single transverse brace can be written as

$$
\begin{aligned}
\bar{U}_{b v}= & \frac{1}{2 E_{b} I_{b}} \int_{0}^{y_{01}^{\prime}}\left(\frac{M_{b v 1}}{y_{01}^{\prime}} y_{0}^{\prime}\right)^{2} d y_{0}^{\prime} \\
& +\frac{1}{2 E_{b} I_{b v}} \int_{0}^{y_{02}^{\prime}}\left(\frac{M_{b v 2}}{y_{02}^{\prime}} y_{0}^{\prime}\right)^{2} d y_{0}^{\prime},
\end{aligned}
$$

where $E_{b} I_{b v}$ is the transverse brace's bending stiffness along radial direction of arch rib and $y_{01}^{\prime}$ and $y_{02}^{\prime}$ represent the distance from the contraflexure point of transverse brace's radial deformation to the main and stable arch ribs, respectively.

The values of $y_{01}^{\prime}$ and $y_{02}^{\prime}$ are closely related to the bending stiffness of arch ribs, the length of the arch rib section, the bending stiffness, and length of the transverse braces. For conventional arch bridges the bending stiffness and inclined angle of two main arch ribs are the same, so $y_{01}^{\prime}=y_{02}^{\prime}$. However, for leaning-type arch bridges, as the bending stiffness of main arch rib is far larger than that of stable arch rib, so $y_{01}^{\prime}>y_{02}^{\prime}$, as shown in Figure 3. In order to obtain the values of $y_{01}^{\prime}$ and $y_{02}^{\prime}$, radial mechanical model of transverse brace along the arch central axis is established when a lateral buckling occurs, as shown in Figure 6(a). The bending moment caused by the transverse braces' radial deflection can be obtained by Castigliano's theorem of material mechanics, as shown in Figure 6(b), and (30) can be given as

$$
e_{2}=\frac{M_{b v 1}}{M_{b v 2}}=\frac{\left(E_{b} I_{b h} d+2 b \cos \phi_{0} G^{I I} T^{I I}\right) G^{I} T^{I}}{\left(E_{b} I_{b h} d+2 b \cos \phi_{0} G^{I} T^{I}\right) G^{I I} T^{I I}}
$$

According to the principle of similar triangles, we arrived at

$$
y_{01}^{\prime}=\frac{e_{2}}{1+e_{2}} b, \quad y_{02}^{\prime}=\frac{1}{1+e_{2}} b
$$

The radial deformation energy of transverse brace can be expressed as

$$
\begin{aligned}
U_{b v}= & \frac{6 E_{b} I_{b v}}{d b} \frac{e_{2}}{1+e_{2}} \int_{s}\left(\beta-\theta_{1}\right)^{2} d s \\
& +\frac{6 E_{b} I_{b v}}{d b} \frac{1}{1+e_{2}} \int_{s}\left(\beta-\theta_{2}\right)^{2} d s \\
= & E_{b} I_{b v} \frac{\left(C_{5}-C_{1}\right)^{2}}{R} D_{3}+E_{b} I_{b v} \frac{C_{3}^{2}}{R} D_{4} \\
& +E_{b} I_{b v} \frac{C_{5}^{2}}{R} D_{4}+E_{b} I_{b v} \frac{C_{3} C_{5}}{R} D_{6},
\end{aligned}
$$




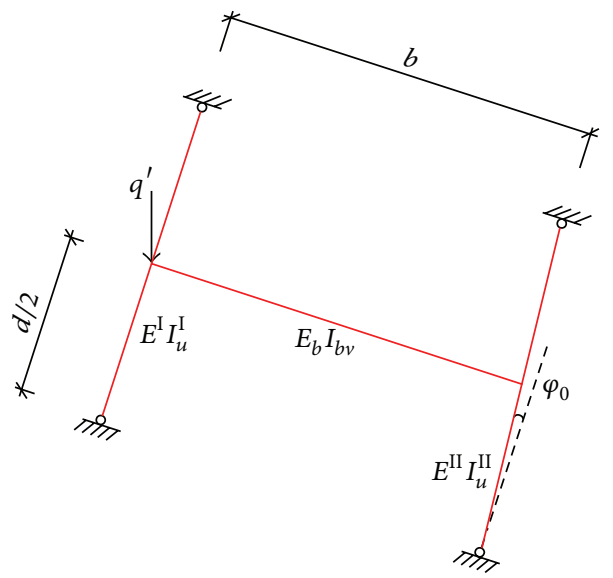

(a) Mechanical model

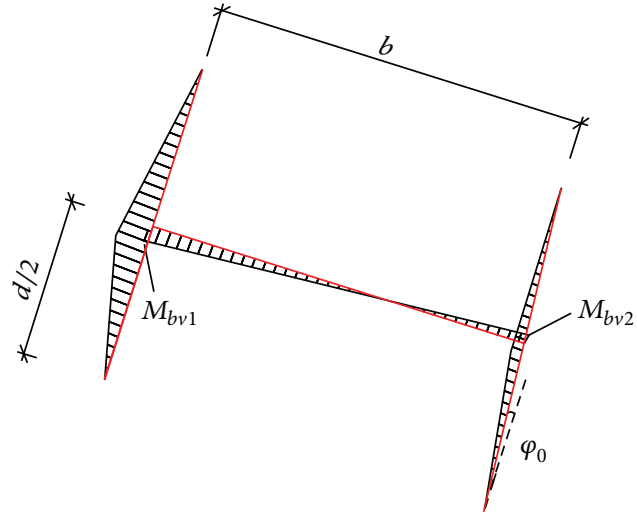

(b) Bending model diagram

FIgURE 6: Mechanical model and moment diagram in radial direction.

where

$D_{3}=\frac{6 n}{b s} \frac{e_{2}}{1+e_{2}} \int_{0}^{\alpha_{1}}\left(1-\cos \frac{2 \pi \varphi}{\alpha_{1}}\right)^{2} R^{2} d \varphi$

$D_{4}=\frac{6 n}{b s} \frac{1}{1+e_{2}} \int_{0}^{\alpha_{2}}\left(1-\cos \frac{2 \pi \varphi}{\alpha_{2}}\right)^{2} R^{2} d \varphi$

$D_{5}=\frac{6 n}{b s} \frac{1}{1+e_{2}} \int_{0}^{\alpha_{2}}\left(1-\cos \frac{2 \pi \varphi}{\alpha_{1}}\right)^{2} R^{2} d \varphi$,

$D_{6}=\frac{6 n}{b s} \frac{1}{1+e_{2}} \int_{0}^{\alpha_{2}}-2\left(1-\cos \frac{2 \pi \varphi}{\alpha_{1}}\right)\left(1-\cos \frac{2 \pi \varphi}{\alpha_{2}}\right) R^{2} d \varphi$.

Assuming the distance between hangers of the main arch rib is $d_{h}$ and its corresponding arc length of arch rib is $d_{h}^{\prime}, d_{h}$ is approximately equal to $d_{h}^{\prime}$ as it is previously assumed that the distance between hangers is small, and the distance between bridge deck and main arch rib is

$$
y(\varphi)=R\left[\cos \left(\varphi-\frac{\alpha_{1}}{2}\right)-\cos \frac{\alpha_{1}}{2}\right] .
$$

As shown in Figure 7 the tension of the hanger is

$$
T=q d_{h}
$$

The horizontal component of hanger tensions is

$$
H=q d_{h} \sin \phi_{1} .
$$

As the lateral displacement is sufficiently small, one arrives at

$$
\sin \phi_{1}=\phi_{1}=\frac{u-u_{d}}{y(\varphi)}
$$

where $y(\varphi)$ is the length of the hanger.

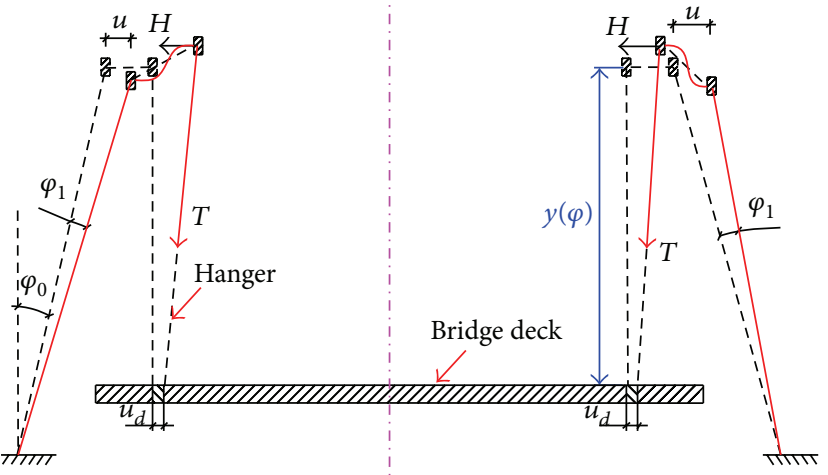

FIGURE 7: Schematic diagram of the horizontal component of hanger tensions with lateral buckling.

The elastic potential energy of arch ribs and bridge deck system caused by the horizontal part of the tension of the hanger is given in

$$
V_{H}=\frac{1}{2} \int_{-L}^{L} H\left(u_{1}-u_{d}\right) \frac{d_{x}}{b_{1}}=q\left(C_{2}-C_{4}\right)^{2} E_{1}
$$

where

$$
E_{1}=\frac{1}{2} \int_{0}^{\alpha_{1}} \frac{R}{2 f} \cos \varphi\left(1-\cos \frac{2 \pi \varphi}{\alpha_{1}}\right)^{2} d \varphi
$$

$f$ is the rise of main arch rib, and in order to simplify its integral, a conservative assumption of $y(\varphi)=f$ is adopted. 
The lateral bending deformation energy of the bridge deck system is given in

$$
\begin{aligned}
U_{d} & =\frac{1}{2} \int_{L} E_{d} I_{d}\left(u_{d}^{\prime \prime}\right)^{2} d l=\frac{1}{2} \int_{s_{1}} E_{d} I_{d} \cos \varphi\left(u_{d}^{\prime \prime}\right)^{2} d s \\
& =E_{d} I_{d} \frac{C_{4}^{2}}{R^{3}} E_{2},
\end{aligned}
$$

where $E_{d} I_{d}$ is the lateral bending stiffness of the bridge deck system

$$
E_{2}=\frac{1}{2} \int_{0}^{\alpha_{1}}\left(\frac{2 \pi}{\alpha_{1}}\right)^{4} \cos \varphi \cos ^{2} \frac{2 \pi \varphi}{\alpha_{1}} \cdot R^{4} d \varphi .
$$

Combined with (4), the potential energy of the external loading is

$$
V=-\frac{1}{2} \int v q d s=-q\left(C_{2}^{2} F_{1}+C_{5}^{2} F_{2} R^{2}\right),
$$

where

$$
\begin{aligned}
& F_{1}=\int_{0}^{\alpha_{1}}\left(\frac{2 \pi}{\alpha_{1}}\right)^{2} \sin ^{2} \frac{2 \pi \varphi}{\alpha_{1}} d \varphi \\
& F_{2}=\int_{0}^{\alpha_{1}}\left(\frac{2 \pi}{\alpha_{1}}\right)^{2} \frac{e_{2}^{2}}{\left(1+e_{2}\right)^{2}} \frac{b^{2}}{R^{2}} \sin ^{2} \frac{2 \pi \varphi}{\alpha_{1}} d \varphi .
\end{aligned}
$$

2.3. The Analytical Solution of Lateral Critical Buckling Loading. The total potential energy of the leaning-type arch bridge can be obtained based on (12), (14), (27), (32), and (38)-(42). According to the principle of stationary potential energy, the values of $C_{i}$ minimizing the function $W\left(C_{i}\right)$ should therefore satisfy the algebraic equations:

$$
\frac{\partial}{\partial C_{i}}(W)=0 \quad(i=1,2, \ldots, 5) .
$$

The existence of nontrivial solutions of (44) for $C_{i}$ requires that the determinant of its coefficient matrix be equal to zero, then we obtained

$$
H_{1} \lambda_{\mathrm{cr}}^{3}+H_{2} \lambda_{\mathrm{cr}}^{2}+H_{3} \lambda_{\mathrm{cr}}+H_{4}=0,
$$

where

$$
\begin{aligned}
H_{1}= & 64 F_{1} F_{2} S_{1} S_{3} E_{1} \\
H_{2}= & 8 S_{5}^{2} S_{3} E_{1} F_{2}-32 S_{1} S_{3} S_{4} F_{1} E_{1}-32 S_{1} S_{2} S_{3} E_{1} F_{2} \\
& +64 S_{1} S_{3} E_{2} F_{1} F_{2} k_{6}+8 S_{1} S_{7}^{2} E_{1} F_{2}+8 S_{1} S_{9}^{2} E_{1} F_{1} \\
& +8 S_{3} S_{6}^{2} E_{1} F_{1}-64 S_{1} S_{3} E_{1} E_{2} F_{2} k_{6} \\
H_{4}= & 4 S_{1} S_{2} S_{9}^{2} E_{2} k_{6}+S_{5}^{2} S_{9}^{2} E_{2} k_{6}-4 S_{1} S_{4} S_{7}^{2} E_{2} k_{6} \\
& -2 S_{5} S_{6} S_{7} S_{9} E_{2} k_{6}-4 S_{1} S_{3} S_{8}^{2} E_{2} k_{6}+4 S_{3} S_{5} S_{6} S_{8} E_{2} k_{6} \\
& +4 S_{1} S_{7} S_{8} S_{9} E_{2} k_{6}-4 S_{2} S_{3} S_{6}^{2} E_{2} k_{6}+S_{6}^{2} S_{7}^{2} E_{2} k_{6} \\
& +16 S_{1} S_{2} S_{3} S_{3} E_{2} k_{6}-4 S_{3} S_{4} S_{5}^{2} E_{2} k_{6} .
\end{aligned}
$$

The lateral buckling critical load coefficient was obtained by solving (45), and then the lateral critical buckling load of leaning-type arch bridge is

$$
q_{\mathrm{cr}}=\lambda_{\mathrm{cr}} \frac{E^{I} I_{u}^{I}}{R^{3}} .
$$

\section{Lateral Buckling Critical Load under the Hinged Boundary Condition of Main Arch Rib}

The following assumptions are made in the derivation process: the main arch ribs are hinged, the stable arch ribs are fixed, and the other assumptions are the same as those stated in Section 2.1. The variables without special explanation are the same as aforementioned.

The torsional angle of arch axis of the main and stable arch ribs is shown as

$$
\begin{aligned}
& \theta_{1}=C_{1} \sin \frac{\pi \varphi}{\alpha_{1}}, \\
& \theta_{2}=C_{3}\left(1-\cos \frac{2 \pi \varphi}{\alpha_{2}}\right) .
\end{aligned}
$$

The lateral displacements of arch axis of the main and stable arch ribs are given as

$$
\begin{aligned}
& u_{1}=C_{2} \sin \frac{\pi \varphi}{\alpha_{1}}, \\
& u_{2}=C_{2} \sin \frac{\pi \varphi}{\alpha_{2}} .
\end{aligned}
$$

The lateral displacements of bridge deck system is given as

$$
u_{d}=C_{4} \sin \frac{\pi \varphi}{\alpha_{1}} .
$$

The global torsional angle of the transverse brace in radial plane caused by arch rib's deflection is

$$
\beta=C_{5} \sin \frac{\pi \varphi}{\alpha_{1}},
$$

where $C_{1}, C_{2}, C_{3}, C_{4}$, and $C_{5}$ are all constants.

The above displacement functions should satisfy the following boundary conditions:

(1) when $\varphi=0$ and $\varphi=\alpha_{1}, \theta_{1}=\beta=0, u_{1}=u_{d}=0$, $\theta_{1}^{\prime \prime}=\beta^{\prime \prime}=0$, and $u_{1}^{\prime \prime}=u_{d}^{\prime \prime}=0$

(2) when $\varphi=0$ and $\varphi=\alpha_{2}, \theta_{2}=0, u_{2}=0, \theta_{2}^{\prime}=0$, and $u_{2}^{\prime \prime}=0$.

The derivation method of the lateral buckling critical load under the hinged boundary condition of main arch ribs is the same as stated above. Due to the limitation of the paper length, the derivation process is omitted; only the calculated results are discussed in the following section. 


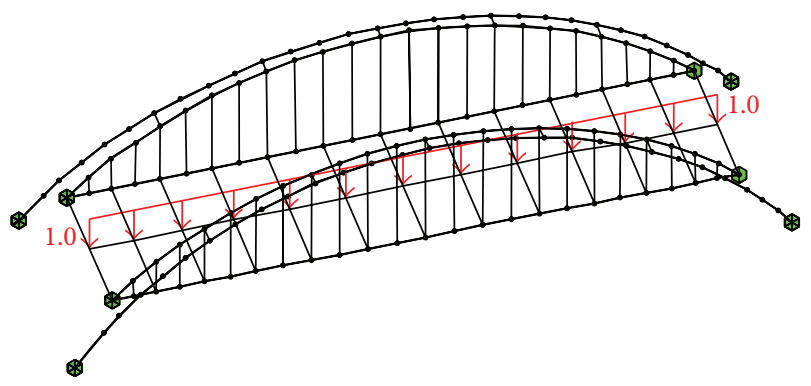

FIGURE 8: The FE model under the fixed boundary condition.

\section{Verification Example}

The leaning-type arch bridge, Shengli Bridge, with a span of $75 \mathrm{~m}$ in Jiangmen city of China is used to verify the accuracy of the derived analytical solution presented in this paper. A three-dimensional finite element model is established by using the Midas/Civil FEM software to calculate arch bridge's lateral buckling critical load for comparison. The main and stable arch ribs of this bridge are both fixed at the arch ends. The FE model is shown in Figure 8.

There are 284 elements and 217 nodes in this FE model. Spatial beam element with 6 degrees of freedom at each node is used to simulate the arch rib, transverse brace, girder, and transverse girder. Spatial truss element with 3 degrees of freedom at each node is used to simulate the hanger. The calculation parameters of the leaning-type bridge are listed in Table 1. Numerical analysis is carried out as the following steps. (1) $1 \mathrm{~N} / \mathrm{m}$ uniform load is applied to the middle of the transverse girder of the bridge deck system. (2) By using Midas/Civil's buckling eigenvalue solver, the eigenvalue $\lambda$ of the bridge is obtained which indicates the lateral buckling critical load of the bridge.

Comparison of the FEM results and the analytical results of the leaning-type arch bridge under fixed and hinged boundary conditions when the stable rib inclined angle is $5^{\circ}$, $7^{\circ}, 9^{\circ}, 11^{\circ}, 13^{\circ}, 15^{\circ}, 17^{\circ}, 19^{\circ}, 21^{\circ}, 24^{\circ}, 27^{\circ}$, and $30^{\circ}$, are shown in Tables 2 and 3 . The contrastive results show that the analytical results agree well with the FEM results with the relative error no more than $3.47 \%, 3.20 \%$ under fixed boundary condition and hinged boundary condition, respectively, which indicate the accuracy of the analytical solution for the stable critical load of the leaning-type arch bridge presented in this paper.

\section{Parametric Analysis}

5.1. Effect of Main Arch Rib's Boundary Condition on the Critical Buckling Load. Figure 9 shows the lateral buckling critical load of a leaning-type arch bridge for both cases of fixed-end main arch ribs and hinged-end main arch ribs. It can be seen from this figure that the lateral buckling critical load of the leaning-type arch bridge with fixed main arch ribs is approximately 1.14 to 1.16 times that of the leaningtype arch bridge with hinged main arch ribs. As the inclined angle increases from $5^{\circ}$ to $30^{\circ}$, the critical load $q_{\mathrm{cr}}$ increases by approximately $11.18 \%$ for cases of fixed-end main arch ribs

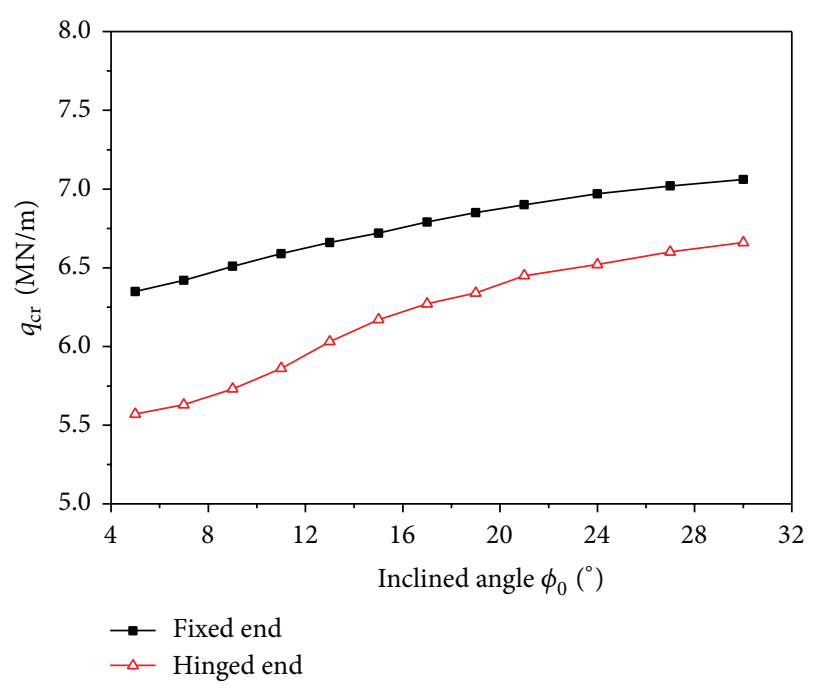

Figure 9: Comparison of critical buckling load under different boundary conditions.

and the critical load $q_{\mathrm{cr}}$ increases by approximately $19.57 \%$ for cases of hinged-end main arch ribs.

\subsection{Effect of the Central Angle on the Critical Buckling Load.} Figure 10 shows the critical load value $q_{\mathrm{cr}}$ when the central angle of the main arch rib and the stable arch rib are the same (the central angle of the main arch rib and the stable arch rib is $87.21^{\circ}$ in this case), and different (the central angle of the main arch rib is $87.21^{\circ}$ and the central angle of the stable arch rib is $104^{\circ}$ in this case) as the inclined angle increases from $5^{\circ}$ to $30^{\circ}$. It can be seen from Figure 10 that the difference of the critical load $q_{\text {cr }}$ between same central angle model and the different central angle model is small enough to be neglected, the former's lateral buckling critical load is only 1.02 to 1.03 times of that of the latter. It indicates that the central angle of the stable arch has relatively less effect on the lateral buckling critical load of the arch bridge, and the central angles of the main arch rib and the stable arch rib can be considered to be the same.

\subsection{Effect of Hanger Tensions and Bridge Deck on Critical} Buckling Load. Figure 11 shows the critical load value with or without considering hanger tensions and bridge deck as the inclined angle increases from $5^{\circ}$ to $30^{\circ}$. From this figure it can be seen that if the hanger tensions and bridge deck are considered, the critical load is $6.664 \mathrm{MN} / \mathrm{m}$ and $7.198 \mathrm{MN} / \mathrm{m}$ when inclined angle is $\phi_{0}=5^{\circ}$ and $30^{\circ}$, respectively. However, if the hanger tensions and the bridge deck are neglected, the critical load is $2.171 \mathrm{MN} / \mathrm{m}$ and $2.451 \mathrm{MN} / \mathrm{m}$ when inclined angle is $\phi_{0}=5^{\circ}$ and $30^{\circ}$, respectively. The critical load increases by 2.94 and 3.07 times, respectively, as compared with that of neglecting the hanger tensions and bridge deck. The results indicate that the hanger tensions and bridge deck can greatly improve the lateral stability of the leaning-type arch bridge. 
TABLE 1: Calculation parameters used in the FE model.

\begin{tabular}{lc}
\hline Span $(\mathrm{m})$ & 75 \\
Rise-span ratio & $1 / 4$ \\
The central angle of main $\operatorname{arch}\left(^{\circ}\right)$ & 87.21 \\
The central angle of stable $\operatorname{arch}\left(^{\circ}\right)$ & 104 \\
Inclined angle of stable $\operatorname{arch~rib~}\left(^{\circ}\right)$ & $5,7,9,11,13,15,17,19,21,24,27$ and 30 \\
Transverse brace length on arch crown $(\mathrm{m})$ & 1.55 \\
Number of transverse brace & 6 \\
Lateral bending stiffness of main arch rib $\left(\mathrm{MN} \cdot \mathrm{m}^{2}\right)$ & $1.414 \times 10^{4}$ \\
Torsional stiffness of main arch rib $\left(\mathrm{MN} \cdot \mathrm{m}^{2}\right)$ & $1.111 \times 10^{3}$ \\
Lateral bending stiffness of stable arch rib $\left(\mathrm{MN} \cdot \mathrm{m}^{2}\right)$ & $1.179 \times 10^{4}$ \\
Torsional stiffness of main arch rib $\left(\mathrm{MN} \cdot \mathrm{m}^{2}\right)$ & $0.926 \times 10^{3}$ \\
Transverse brace's bending stiffness along radial direction of arch rib $\left(\mathrm{MN} \cdot \mathrm{m}^{2}\right)$ & 36.84 \\
Transverse brace's bending stiffness along tangential direction of arch rib $\left(\mathrm{MN} \cdot \mathrm{m}^{2}\right)$ & $1.058 \times 10^{2}$ \\
Lateral bending stiffness of girder $\left(\mathrm{MN} \cdot \mathrm{m}^{2}\right)$ & $2.3 \times 10^{7}$ \\
Vertical bending stiffness of girder $\left(\mathrm{MN} \cdot \mathrm{m}^{2}\right)$ & $5.52 \times 10^{4}$ \\
Lateral bending stiffness of transverse beam $\left(\mathrm{MN} \cdot \mathrm{m}^{2}\right)$ & $1.15 \times 10^{4}$ \\
Vertical bending stiffness of transverse beam $\left(\mathrm{MN} \cdot \mathrm{m}^{2}\right)$ & $7.187 \times 10^{2}$ \\
The cross section area of hangers $\left(\mathrm{m}^{2}\right)$ & $1.25664 \times 10^{-3}$ \\
Poisson's ratio & 0.2
\end{tabular}

TABLE 2: Comparison between the analytical solution and FEM results under fixed boundary condition.

\begin{tabular}{lcccccccccccc}
\hline Inclined angle & $5^{\circ}$ & $7^{\circ}$ & $9^{\circ}$ & $11^{\circ}$ & $13^{\circ}$ & $15^{\circ}$ & $17^{\circ}$ & $19^{\circ}$ & $21^{\circ}$ & $24^{\circ}$ & $27^{\circ}$ & $30^{\circ}$ \\
\hline Analytical (MN/m) & 6.35 & 6.42 & 6.51 & 6.59 & 6.66 & 6.72 & 6.79 & 6.85 & 6.90 & 6.97 & 7.02 & 7.06 \\
FEM (MN/m) & 6.42 & 6.45 & 6.48 & 6.51 & 6.53 & 6.55 & 6.59 & 6.62 & 6.71 & 6.74 & 6.87 & 6.90 \\
Error (\%) & 1.09 & 0.47 & 0.46 & 1.23 & 1.99 & 2.60 & 3.03 & 3.47 & 2.83 & 3.41 & 2.18 & 2.32 \\
\hline
\end{tabular}

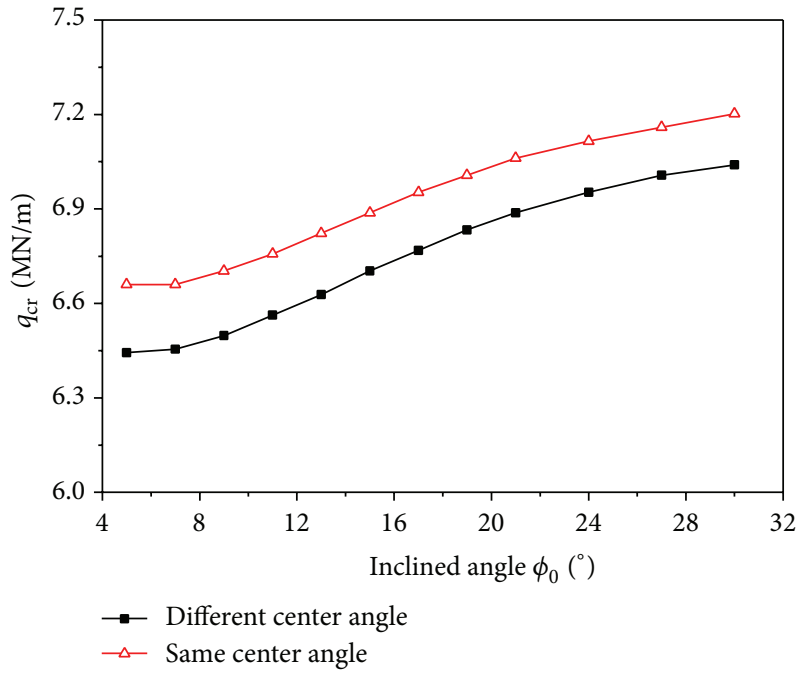

FIGURE 10: Comparison of critical buckling load under the same and different central angle.

5.4. Effect of the Stable Arch Rib on Critical Buckling Load. Figure 12 shows the critical load $q_{\mathrm{cr}}$ of the models with or without stable arch ribs as the inclined angle increases from $5^{\circ}$ to $30^{\circ}$. From this figure it can be seen that the critical load of the models with stable arch ribs is always larger than that

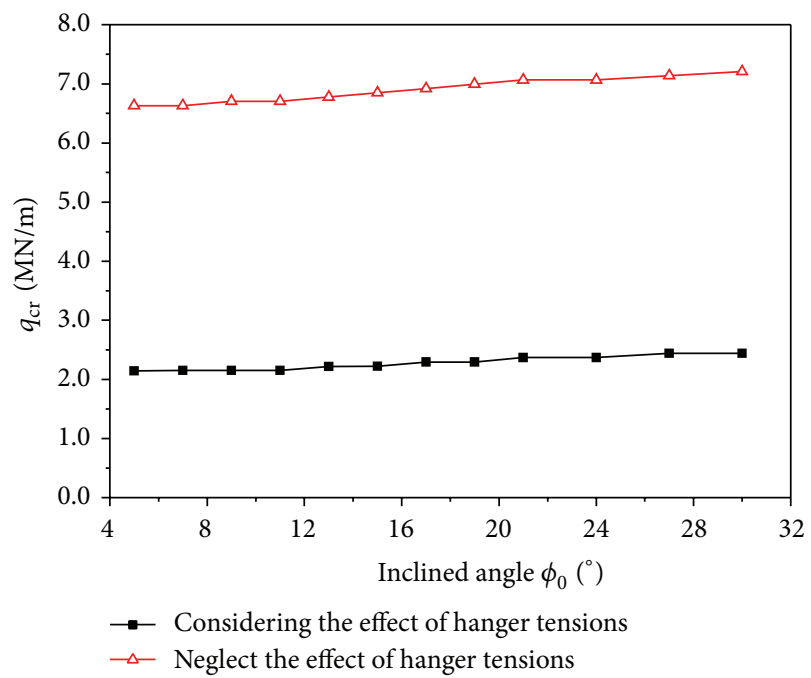

FIGURE 11: Comparison of critical buckling load with and without hanger tensions effect.

of the models without stable arch ribs and the percentage of increase is from $31.5 \%$ and $42.1 \%$ as the inclined angle increased. The results indicate that the effect of stable arch rib on critical load is significant. 
TABLE 3: Comparison between analytical solution and FEM results under hinged boundary condition.

\begin{tabular}{lcccccccccccc}
\hline Inclined angle & $5^{\circ}$ & $7^{\circ}$ & $9^{\circ}$ & $11^{\circ}$ & $13^{\circ}$ & $15^{\circ}$ & $17^{\circ}$ & $19^{\circ}$ & $21^{\circ}$ & $24^{\circ}$ & $27^{\circ}$ & $30^{\circ}$ \\
\hline Analytical (MN/m) & 5.57 & 5.63 & 5.73 & 5.86 & 6.03 & 6.17 & 6.27 & 6.34 & 6.45 & 6.52 & 6.60 & 6.66 \\
FEM (MN/m) & 5.70 & 5.75 & 5.87 & 5.90 & 5.96 & 6.00 & 6.09 & 6.19 & 6.25 & 6.32 & 6.40 & 6.47 \\
Error (\%) & 2.28 & 2.09 & 2.38 & 0.68 & 1.17 & 2.83 & 2.96 & 2.42 & 3.20 & 3.16 & 3.13 & 2.93 \\
\hline
\end{tabular}

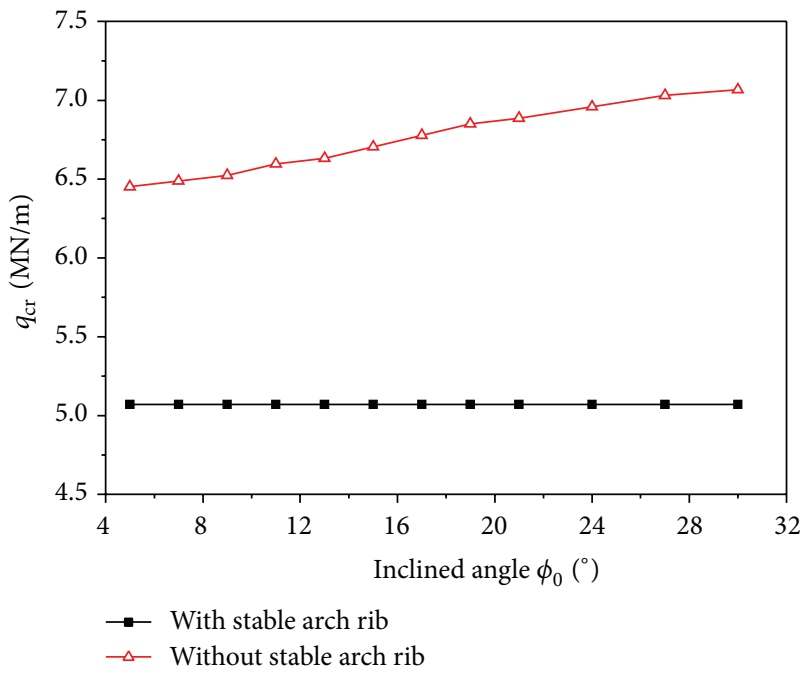

FIGURE 12: Comparison of critical buckling load with and without stable arch rib.

\section{Conclusions}

This paper has derived an analytical solution for lateral buckling critical load of leaning-type arch bridge based on the Ritz method, and the accuracy of this solution has been verified through a numerical example. Moreover, parametric analysis is carried out in order to investigate how changes in certain design parameters would affect the critical load of the leaning-type arch bridges by using the analytical solution presented in this paper. The main conclusions are as follows.

(1) The analytical solution present in this paper can be used to calculate the lateral buckling critical load of the leaning-type arch bridges in different cases, including the central angles of the main arch rib and stable arch rib which are different; both the main arch ribs and the stable arch ribs are fixed in their ends, the main arch ribs with hinged boundary condition while the stable arch ribs with fixed boundary conditions. From the comparison of the analytical results and the FEM results, the analytical solution presented in this paper is verified to be sufficiently accurate.

(2) The lateral buckling critical load under fixed boundary condition is approximately 1.14 to 1.16 times as large as that under hinged boundary conditions, which indicate that the lateral stability of the former is better than that of the latter.

(3) The critical load with the same central angles is slightly bigger than the one with different central angles, and the former's lateral buckling critical load is 1.02 to 1.03 times as big as that of the latter. It indicates that the central angle of the stable arch has relatively less influence on the lateral buckling critical load of the leaning-type arch bridge, and therefore the central angles of the main arch and the stable arch can be considered to be the same for convenience.

(4) Stable arch rib can significantly increase the lateral buckling critical load $q_{\text {cr }}$ of leaning-type arch bridge by $31.5 \%$ to $42.1 \%$ when stable arch rib is considered under the fixed boundary condition, where the value of $q_{\mathrm{cr}}$ increases as the inclined angle of stable arch rib increases.

(5) The hanger tensions and bridge deck have significant effect on the critical load, and when considering the effect of hanger tensions and bridge deck, the critical load can improve by 2.94 to 3.07 times.

\section{Notations}

$\theta_{1}, \theta_{2}$ : The torsional angle of the main and stable arch ribs

$u_{1}, u_{2}$ : The lateral displacement of the main and stable arch ribs under the global coordinate

$u_{1}^{I}, u_{1}^{I I}$ : The lateral displacement of the main and stable arch ribs under the local coordinate

$u_{d}$ : The lateral displacement of bridge deck system

$\phi_{0}$ : The angle between the main arch rib and the stable arch rib

$\varphi$ : $\quad$ The angle of a position in the arch ribs

$\alpha_{1}, \alpha_{2}$ : The central angle of the main and stable arch ribs

$\beta$ : $\quad$ The global torsional angle of the transverse brace caused by deformation of arch rib in radial plane

$R: \quad$ The radius of the main and the stable arch ribs

$b(x): \quad$ The distance between the main arch rib and the stable arch rib

$b_{0}$ : The length of the transverse brace at the arch crown

$h$ : The distance between the main and stable arch ribs at quarter span

$d$ : The distance between the transverse braces

$d_{h}$ : The distance between the hangers

$K_{u}^{I}, K_{u}^{I I}$ : The lateral deflection curvature of the main and stable arch ribs respectively

$K_{w}^{I}, K_{w}^{I I}$ : The torsional deflection curvatures of the main and stable arch ribs, respectively 
$U_{u}^{I}, U_{u}^{I I}: \quad$ The lateral bending deformation energy of the main and stable arch ribs, respectively

$U_{w}^{I}, U_{w}^{I I}$ : The torsional deformation energy of the main and stable arch ribs, respectively

$U_{c u}^{I}, U_{c u}^{I I}: \quad$ The local bending deformation energy of the main and stable arch ribs, respectively

$U_{b v}: \quad$ The bending deformation energy of the transverse braces in radial directions

$U_{b H}$ : The bending deformation energy of the transverse braces in tangential directions

$V_{H}$ : The elastic potential energy of the arch ribs and the bridge deck system under the horizontal component of the hanger tensions

$V_{d}$ : The elastic potential energy of bridge deck system

$V: \quad$ The potential energy of external loading

$\bar{U}_{c u}^{I}, \bar{U}_{c u}^{I I}: \quad$ The single-panel arch rib local bending energy of main and stable arch ribs

$\bar{U}_{b H}$ : The tangential bending deformation energy of the single transverse brace

$\bar{U}_{b v}: \quad$ The radial deformation energy of a single transverse brace

$E^{I} I_{u}^{I}, E^{I I} I_{u}^{I I}$ : The lateral bending stiffness of the main and stable arch ribs

$G^{I} T^{I}, G^{I I} T^{I I}$ : The torsional stiffness of the main and stable arch ribs

$E_{b} I_{b h}$ : The bending stiffness of transverse brace along tangential direction of arch rib

$E_{b} I_{b v}$ : The bending stiffness of transverse brace along radial direction of arch rib

$M_{c u 1}, M_{c u 2}$ : The bending moments of main and stable arch ribs along radial direction

$M_{b h 1}, M_{b h 2}$ : The tangential bending moment of transverse brace near the main and stable arch ribs

$M_{b v 1}, M_{b v 2}$ : The vertical bending moment on both ends of transverse brace near the main and stable arch ribs

$y_{01}, y_{02}: \quad$ The distances from the contraflexure point of transverse brace tangential deformation to main and stable arch ribs, respectively

$y_{01}^{\prime}, y_{02}^{\prime}: \quad$ The distance from the vertical contraflexure point of transverse brace's radial deformation to main and stable arch ribs, respectively

$\gamma_{1}, \gamma_{3}$ : The tangential angular rotation of the transverse brace at the intersection points between the main and stable arch rib and the transverse brace, respectively

$\gamma_{2}, \gamma_{4}$ : The tangential angular rotation of the main and stable arch rib at the intersection points between the main and stable arch rib and the transverse brace, respectively.

\section{Conflict of Interests}

The authors declare that there is no conflict of interests regarding the publication of this paper.

\section{Acknowledgments}

This study was sponsored by the National Natural Science Foundation of China (nos. 11272095, 51378133, and 51208123), the Science and Technology Planning Major Project of Guangzhou City (no. 2011Y2-00006), the Key Technological Innovation Program of Guangdong Ministry Education (no. 2012CXZD0028), the Key Project supported by the Natural Science Foundation of Guangdong Province (no. S2011030002800), and the Talent Introduction Project supported by the Higher Education Department of Guangdong Province in 2012.

\section{References}

[1] A.-R. Liu, Q.-C. Yu, R. Song, and J.-P. Zhang, "Dynamic stability of leaning-type arch bridge under earthquake," Journal of Shenzhen University Science and Engineering, vol. 27, no. 3, pp. 286-290, 2010 (Chinese).

[2] A. C. Franciso, Acro Colour Thematic Architecture, Acro Editorial, 1989.

[3] R. C. Xiao, H. T. Sun, and L. J. Jia, "Kunshan Yufeng bridgedesign of the first long-span leaning-type arch bridge without thrust," China Civil Engineering Journal, vol. 38, no. 1, pp. 7883, 2005.

[4] N.-H. Lim and Y.-J. Kang, "Out of plane stability of circular arches," International Journal of Mechanical Sciences, vol. 46, no. 8, pp. 1115-1137, 2004.

[5] Y.-L. Pi and M. A. Bradford, "Effects of prebuckling deformations on the elastic flexural-torsional buckling of laterally fixed arches," International Journal of Mechanical Sciences, vol. 46, no. 2, pp. 321-342, 2004.

[6] Y.-L. Pi, M. A. Bradford, and F. Tin-Loi, "Flexural-torsional buckling of shallow arches with open thin-walled section under uniform radial loads," Thin-Walled Structures, vol. 45, no. 3, pp. 352-362, 2007.

[7] Y. Chen and J. Feng, "Elastic stability of shallow pin-ended parabolic arches subjected to step loads," Journal of Central South University of Technology, vol. 17, no. 1, pp. 156-162, 2010.

[8] P. D. B. La, R. C. Spoorenber, H. H. Sniijder, and J. C. D. Hoenderkamp, "Out-of-plane stability of roller bent archesan experimental investigation," Journal of Constructional Steel Research, vol. 81, no. 1, pp. 20-34, 2013.

[9] M. A. Bradford and Y.-L. Pi, "A new analytical solution for lateral-torsional buckling of arches under axial uniform compression," Engineering Structures, vol. 41, no. 1, pp. 14-23, 2012.

[10] C. Dou, Y. L. Guo, S. Y. Zhao, Y. L. Pi, and M. A. Braford, "Elastic out-of-plane buckling load of circular steel tubular truss arches incorporating shearing effects," Engineering Structures, vol. 52, no. 7, pp. 696-706, 2013.

[11] W. Jin and G. Zhao, "Lateral buckling of X-type twin ribbed arch braced with transverse beams," China Civil Engineering Journal, vol. 22, no. 2, pp. 44-54, 1989 (Chinese).

[12] Z. Liu and Z.-T. Lu, "Lateral buckling load of tied-arch bridges with transverse braces," Engineering Mechanics, vol. 21, no. 3, pp. 21-54, 2004 (Chinese).

[13] Z. F. Xiang, "Practical calculation of the lateral stability of the midhight-deck arch bridge," Journal of Chongqing Jiaotong Institute, vol. 14, no. 1, pp. 27-33, 1995 (Chinese).

[14] D. Y. Gu, H. Chen, Y. Wang, and F. Hu, "Stability analysis of the Chaozhou Hanjiang River Northen leaning-type arch 
bridge," Journal of Highway and Transportation Research and Development, vol. 23, no. 3, pp. 100-103, 1995 (Chinese).

[15] A.-R. Liu, F.-L. Shen, J.-T. Kuang, J.-P. Zhang, and Q.-C. $\mathrm{Yu}$, "Calculation method for lateral buckling critical load of leaning-type arch rib system," Engineering Mechanics, vol. 28, no. 12, pp. 166-172, 2011 (Chinese).

[16] H. Shafiee, M. H. Naei, and M. R. Eslami, "In-plane and out-ofplane buckling of arches made of FGM," International Journal of Mechanical Sciences, vol. 48, no. 8, pp. 907-915, 2006. 


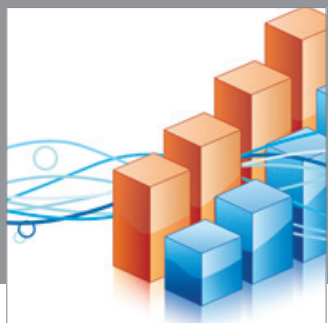

Advances in

Operations Research

mansans

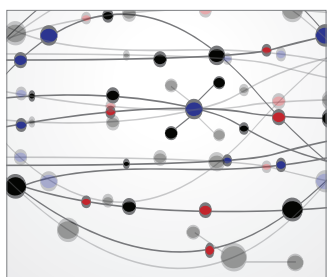

The Scientific World Journal
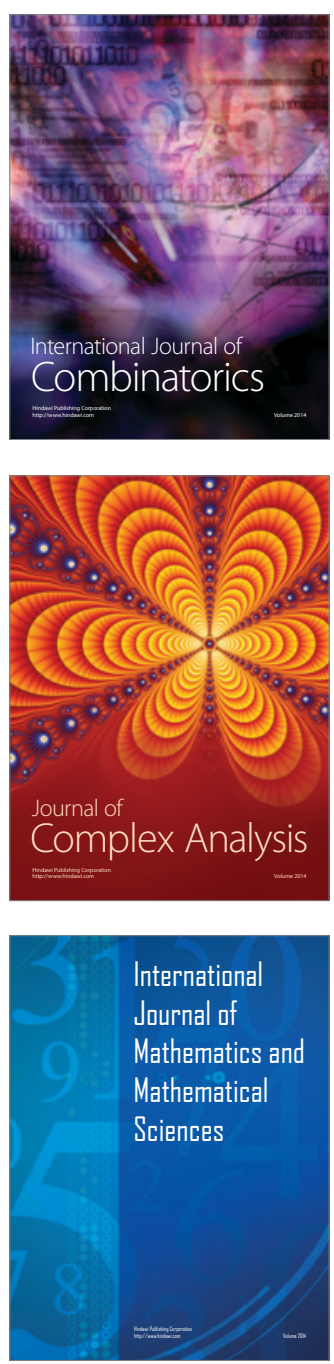
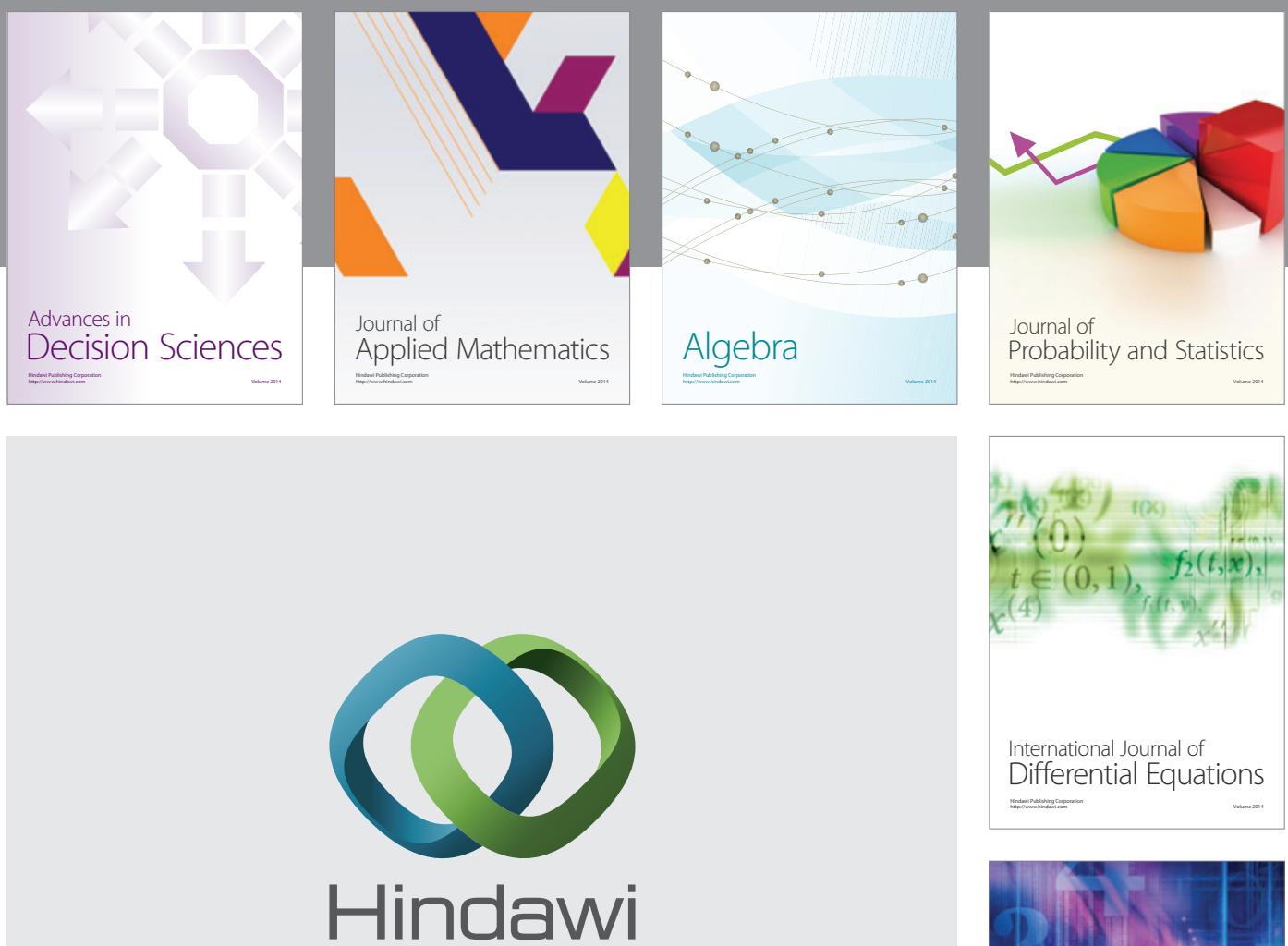

Submit your manuscripts at http://www.hindawi.com
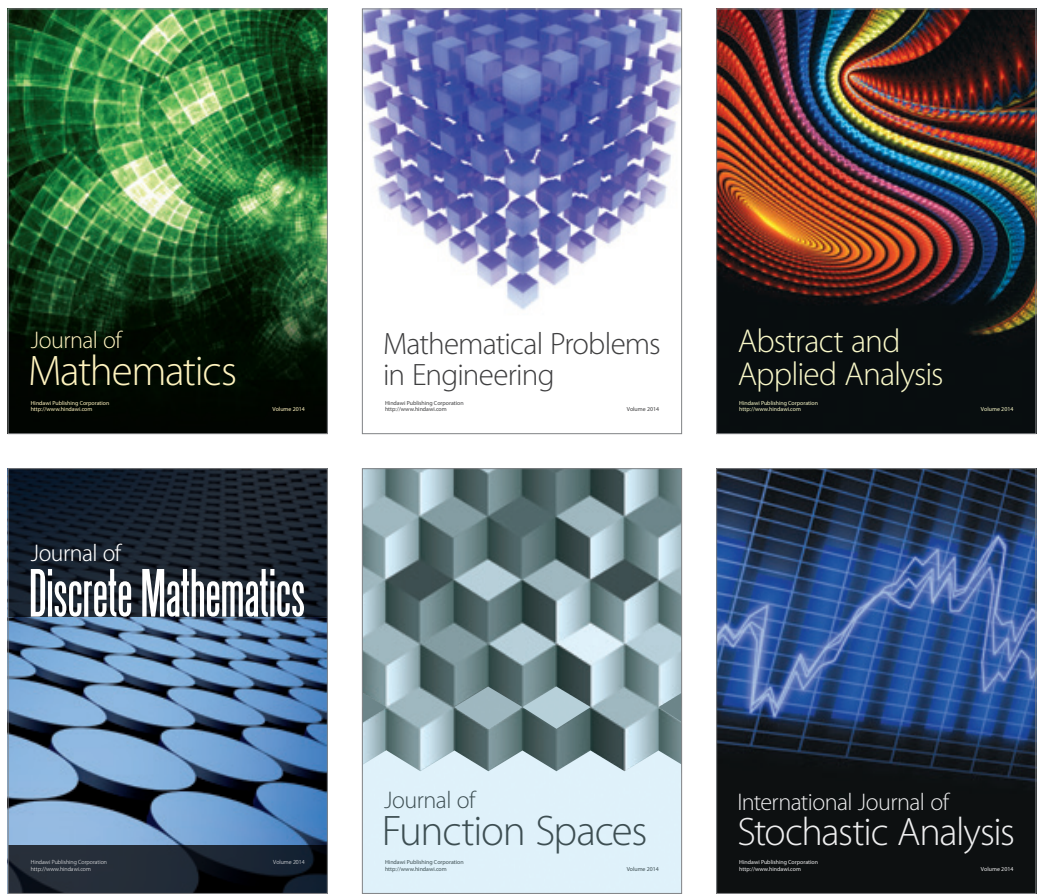

Journal of

Function Spaces

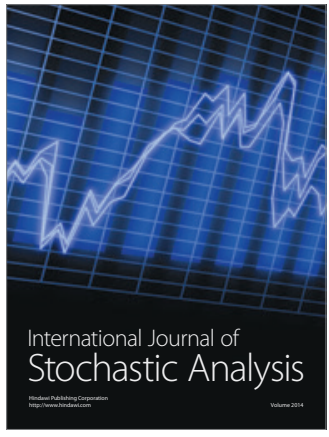

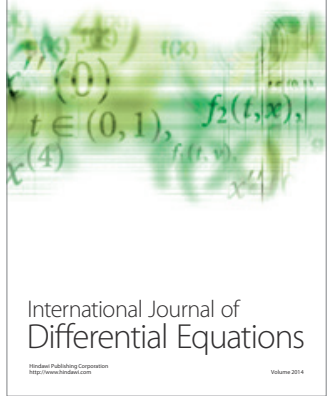
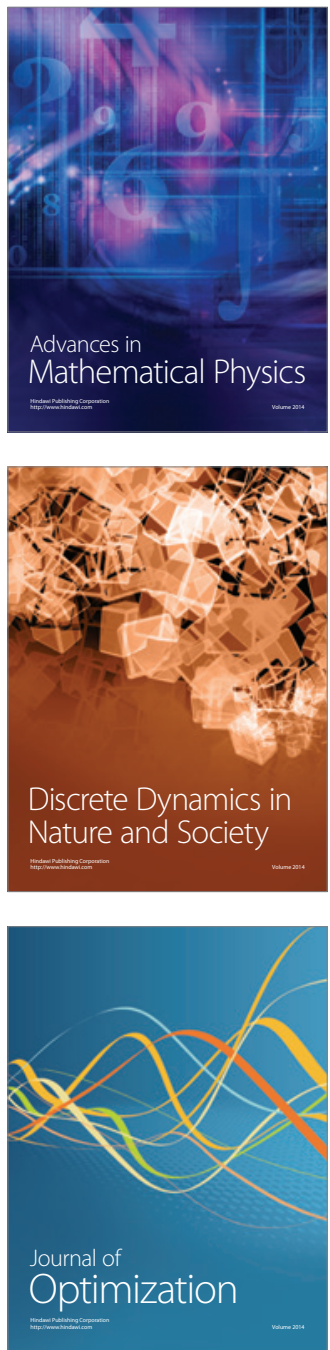